\title{
Tracing estuarine metal release from river-borne particulates in Iceland
}

Burton K.W. ${ }^{1}$, ARCHER C. ${ }^{2}$, Gislason S. R. ${ }^{3}$, POGGE VON STRANDMANN P. ${ }^{4}$, MCCOY-WeSt, A. ${ }^{5}$, VANCE D. ${ }^{2}$

${ }^{1}$ Department of Earth Sciences, Durham Univ., Durham, UK

${ }^{2}$ Department of Earth Sciences, ETH Zurich, Switzerland

${ }^{3}$ Institute of Earth Sciences, University of Iceland, Iceland

${ }^{4}$ Department of Earth Sciences, UCL, London, UK

${ }^{5}$ School of Earth, Atmospheric and Environment, Monash

University, Melbourne, Australia.

Rivers are the dominant source of many elements in the ocean, but the dissolved input from the continents is not balanced by hydrothermal or sedimentary exchange with the ocean crust, often taken to indicate that the oceans are not in steady-state. Riverine flux estimates are, however, usually based on dissolved species alone and neglect the impact of continued exchange or reaction of riverine particulates in seawater. Recent studies indicate that element release from such particulates in seawater is significant, and for many elements may be equal to or greater than the dissolved riverine flux.

Here we present metal stable isotope data (including $\mathrm{Nd}$, $\mathrm{Fe}, \mathrm{Zn}$ and $\mathrm{Cu}$ ) for estuarine particulates and water from from the Borgarfjörður estuary in W Iceland. In general, river waters possess low elemental concentrations, and thus are highly sensitive to loss or gain during estuarine transfer. Metal stable isotopes all show variations in water that are inconsistent with simple conservative mixing with seawater. Stable isotope shifts might be taken to indicate colloidal flocculation and element removal from water. Rather the waters show a systematic increase in concentration at salinities between 0.05 and 10 , consistent with elemental supply in the estuary itself. Isotope and elemental shifts are consistent with particulates being the elemental source, with water gains mirrored by particulate loss. The question remains as to the source of these elements in the particulates. Some have suggested that this results from weathering of primary basaltic particulates, others that this is from the dissolution of Fe-oxyhydroxides. Sequential extraction from these particulates indicates, however, that organic material is the dominant source of transition metals, and rare earth elements. These results, illustrate that elemental release from particulates in estuaries is a substantial source to seawater, but that this release is strongly controlled by the dominant labile phase present in those particulates, which in turn is regulated by biogeochemical processes in river catchments. 